\title{
Evaluation of Transit Signal Priority for Bus Rapid Transit in Heterogeneous Traffic Flow
}

\author{
Mohammadhossein ABBASI ${ }^{\star}$, Mansour Hadji HOSSEINLOU, Arash SARRESHTEHDARI, Sadko MANDZUKA
}

\begin{abstract}
Inefficient traffic signal control at intersections causes vehicle delays, increased fuel consumption, and vehicle emissions. With respect to the large number of fixed signalized intersections along the $7^{\text {th }}$ line of Tehran BRT, passengers experience long delays and travel time while BRT is defined as a high-quality bus-based transit system that delivers fast and efficient service according to literature. Due to constraints on increasing supply, actuated traffic signal (ATS) and public transportation priority (PTP) are some of the possible signal control methods that can reduce the above-mentioned problems. In this paper, the $7^{\text {th }}$ line of Tehran BRT is simulated using Aimsun. ATS and PTP have been simulated and traffic, environmental and economic indicators of transit and non-transit vehicles have been derived. Finally, a cost-benefit analysis is conducted to calculate the net present value (NPV), internal rate of return (IRR) and payback period (PP) of investment. Results show a decrease in travel time, delay, stop time, fuel consumption and pollutant emissions and an increase in average speed and flow at intersections. The payback period is estimated to be approximately two months, indicating a short-term policy and other economic indices confirm the profitability of project.
\end{abstract}

Keywords: Actuated Traffic Signal; Aimsun; Cost-Benefit Analysis (CBA); Microscopic Traffic Simulation; Payback Period; Public Transportation Priority

\section{INTRODUCTION}

Intersections are the most important traffic bottlenecks in urban environment. Due to congestion in Tehran, 50.7\% of trips are facing delays on average [1], and enhancing traffic node performances with an integrated approach is vital and essential for sustainability of transport system. Concerning a large number of vehicles and crowded intersections in highly crowded areas of Tehran, fixed traffic signal timing of the intersections leads to increasing delays, fuel consumption and pollutant emissions of transit and non-transit vehicles. Since geometry design changes are not possible due to space limitations, therefore application of signal control methods such as using actuated traffic signals and public transportation priority could be appropriate solutions. Regarding the $23 \%$ share of transport sector in pollutant emissions [2], many researchers believe that public transport development is an effective way to reduce traffic congestions and air pollution in metropolises [3].

There are some standards and guidelines providing theoretical foundations for the design, analysis, and evaluation of BRT systems, the most well-known could belong to the Institute for Transportation and Development Policy (ITDP). The BRT Planning guideline begins with an overview of the BRT and then goes on explaining the planning process including operational design, financial modeling, physical design, land-use integration, multimodal transportation, preparation and developments of the business plan, communications and marketing, contract preparation, mode choice and fare collection technologies, final evaluation and construction. Assessing some performance indicators of public transportation systems such as average delay, average speed and pollutant emissions in developed countries indicate that the Line 7 of Tehran's BRT does not operate properly [3-10]. Due to the fact that more than $50 \%$ of the bus fleet in the Line 7 of Tehran's BRT is more than 15 years old and with regard to a large number of signalized intersections along the $18 \mathrm{~km}$ route of this line, the amount of pollutants in these intersections is considerably high. Also, the average speed on this line $(20 \mathrm{~km} / \mathrm{h})$ is much lower than various standards (such as the BRT Standard) and buses experience a lot of delay along the route. Hence, local authorities have taken action to increase the capacity, efficiency and utility of public transportation systems by developing bus rapid transit system, dedicated bus routes and transport signal priority. Public transport vehicles are designed to move large number of commuters in crowded areas. So, many believe that public transport vehicles should be prioritized at intersections [10]. Transit Signal Priority (TSP) was defined by Smith et al. as an operational strategy that provides efficient and reliable transit operation by providing priority to transit vehicles at signalized intersections [11], which leads to lower delays and improves the level of service [12]. Various methods of TSP could be implemented including permanent (passive)one which is suitable for locales where bus volumes are high and the dwell times are predictable [13], temporary (active, including green extension, red truncation, actuated transit phases, phase insertion, and phase rotation) that only modifies the signal when a TSP equipped vehicle is detected. And also, adaptive priority TSP which considers both transit and non-transit delays and adjusts signal timing in a way that transit vehicles experience lower delay and non-transit vehicles do not affect this strategy significantly [14]. Regarding various methods of TSP, traffic and economic aspects of the individual policies should be considered [15].

In this paper, the operation of the $7^{\text {th }}$ line of Tehran's BRT has been evaluated and with reference to long delays and high fuel consumption, some operational strategies such as actuated traffic signals and public transportation priority have been examined to enhance the efficiency and utility of BRT in Tehran. In actuated traffic signals, allocation of green time to the approaches is based on the volume of traffic passing at any time and could create coordination in the urban transportation network. Many researchers have conducted studies on the subject of TSP and actuated traffic signals. Abbasi et al. (2020) evaluated $1^{\text {st }}$ line of Tehran's BRT using Aimsun under different operational scenarios. They concluded that actuated traffic signals have many benefits, for instance, travel times, $\mathrm{CO}$ and NOx emissions and fuel consumption were reduced by $6.31 \%, 25.9 \%, 6.2 \%$ and $5.26 \%$, respectively [10]. Vilarinho et al. (2017) presented a person-based traffic 
signal control strategy for an isolated intersection. The traffic signals allocate green time based on an auction-like schema. Results revealed that the proposed signal control system reduced total person delay at the intersection and effectively provided priority to vehicles with more occupancy [16]. Ilahi and Irawan (2013) simulated BRT lines in Indonesia using Aimsun under different scenarios. They concluded that TSP, as the best scenario, reduced travel times and delays by $41 \%$ and $57 \%$, respectively [17]. Shaaban and Ghanim (2018) investigated the impact of implementing a TSP treatment along a major arterial. A micro simulation approach was used to model and evaluate the potential benefits of TSP for bus transit vehicles. The network was built in VISSIM and considered different peak hours for performance assessment. The results showed that bus travel times were reduced by more than $40 \%$ and in some cases had a minimal negative effect on the general traffic [18]. Ghanim et al. (2013) conducted a microscopic simulation study to identify the impact of implementing TSP strategies on an arterial corridor segment at Michigan State University. Microscopic simulation was carried out in VISSIM, and results showed that transit vehicles benefit from the provided preferential treatments [19]. Yang et al. (2012) analyzed two proposed control strategies using a microscopic traffic simulator, VISSIM. Signal priority used advanced detection, a TSP strategy that detected one cycle in advance of bus arrival. Based on the evaluation of indicators such as delay, travel speed and reliability, the simulation results showed that proposed control strategy has remarkably improved the efficiency of public transit [20]. Wang and Weng (2010) proposed a cycle-flexible actuated control method to improve the operating efficiency of an intersection using VISSIM. Results indicated that cycle-flexible actuated control method improves the operational efficiency of vehicles of other phases compared to the cycle-fixed actuated control method [21].

According to State of The Art (SOTA) review, it was concluded that simulation is the process of creating an abstract representation to represent important aspects of the real world. It is capable of examining changes in existing systems and studying systems that are in the design phase. Since none of the signalized intersections on the route of the $7^{\text {th }}$ line of Tehran's BRT are equipped with actuated traffic signal timing and TSP treatment, microscopic traffic simulation tool, Aimsun, has been used to study TSP and actuated signals in Tehran's BRT. Most of the previous studies focused on an isolated intersection or an arterial road. However, in this paper, the $7^{\text {th }}$ line of Tehran's BRT has been considered as the case study which connects the southernmost point of Tehran to the northernmost point through an $18 \mathrm{~km}$ dedicated BRT route. Also, unlike previous studies, this paper focuses on the overall bus schedule rather than a single trip. In addition, in this paper all of the control systems of intersections along the route are changed to the actuated signal timing to remove the barriers and disadvantages of fixed signal timing and to obtain rapid recognition of bus priority requests. Another contribution of this paper is considering the economic aspect of scenario and conducting a Cost-Benefit Analysis (CBA). Besides, less attention has been paid to the pollutant emissions and fuel consumption of transit and non-transit vehicles, also regarding the importance of longitudinal slope in fuel consumption and pollutant emissions, this factor has been considered in this paper.

This paper is structured as follows: Section 2 is about the used methodology, section 3 addresses traffic simulation, section 4 reviews and discusses the results, and section 5 outlines the major conclusions.

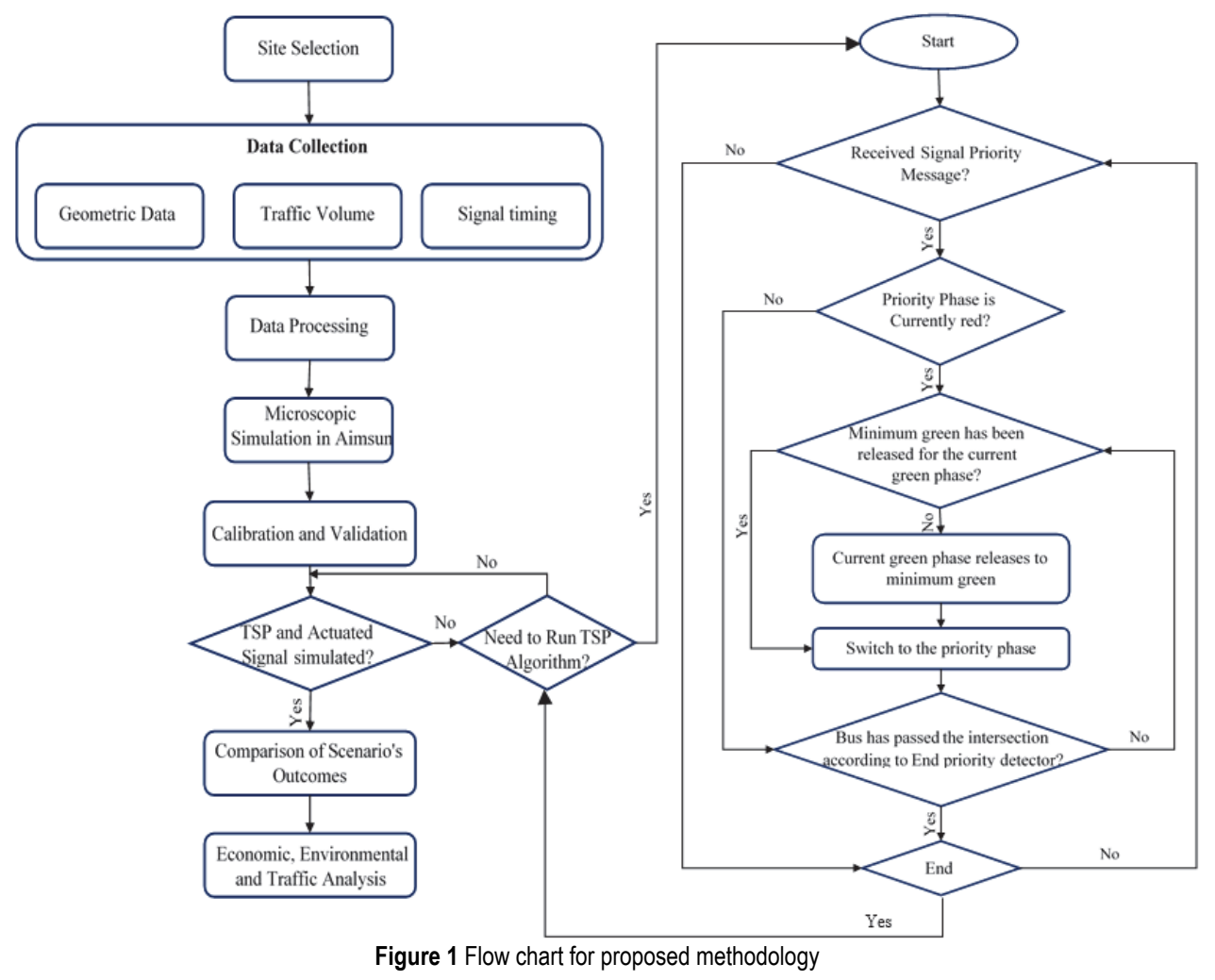




\section{METHODOLOGY}

Nowadays, traffic simulation tools are used to evaluate the feasibility of implementing a new system or improving the performance of an existing system. Considering the complexity of traffic and human behavior, using an appropriate simulation tool is necessary. Aimsun is one of the microscopic traffic simulation tools to study various traffic management strategies and numerous measures of effectiveness (MOEs).

The $7^{\text {th }}$ line of Tehran's BRT has been selected to study. A large amount of data required for microscopic simulation including geometry data, traffic volume and signal timing data have been obtained from the Transportation and Traffic Organization of Tehran Municipality and field survey [22]. The $7^{\text {th }}$ line of Tehran's BRT has been simulated in Aimsun, and after calibration and validation of the model, TSP and actuated traffic signal timing have been simulated to evaluate the traffic, environmental and economic indicators of proposed scenario. The flowchart of the proposed methodology is shown in Fig. 1.

According to Fig. 1, after selecting the $7^{\text {th }}$ line of Tehran's BRT and its impact area, various data have been collected to analyze the current situation including traffic volume, geometry-design characteristics such as route slope, number of lanes, lane widths, and etc. along with traffic-signal characteristics such as timing schedule, duration of each phase and their sequence. After preparing and processing data, simulation of the current situation was performed in Aimsun. In addition, in order to accurately simulate the reality, various parameters were selected for model calibration.

After calibration, the validity of the model was examined using data different from the data used in the calibration phase. Therefore, the proposed scenario was simulated to prioritize the bus which approaches the intersection and announces a request. The control algorithm (the right part of Fig. 1) starts and adapts the bus intersection crossing. After the simulation, the results of each scenario are extracted and various traffic, economic and environmental aspects are compared.

\subsection{Case Study}

Tehran, the capital of Iran, has a population of $8,694,000$. It is also known as Iran's largest and the most crowded urban area, the largest city in Western Asia, and the 19th largest city in the world [23]. Due to the lack of a decent and highly efficient public transportation system, more than 3 million cars are on the roads.

The $7^{\text {th }}$ line of Tehran's BRT, as illustrated in Fig. 2, is one of the longest public transportation lines in Tehran, transporting thousands of passengers daily between Tehran's northernmost (Tajrish Square) and southernmost part (Railway Station). The bus route covers the entire Valiasr Street, one of the longest streets in the Middle East with a length of $18 \mathrm{~km}$. The information of the $7^{\text {th }}$ line of Tehran's BRT is summarized in Tab. 1.

Regarding the importance of TSP treatment at intersections, this technology has been implemented in many developed and developing countries but despite numerous intersections along the route of the $7^{\text {th }}$ line of
Tehran's BRT, no intersection is equipped with this technology. There are 20 intersections along the $7^{\text {th }}$ line of Tehran's BRT, in which 13 intersections are signalized but none of them is equipped with TSP treatment.

Table 1 An overview of the 7th line of Tehran's BRT

\begin{tabular}{|c|c|c|}
\hline \multicolumn{3}{|c|}{ Table 1 An overview of the 7th line of Tehran's BRT } \\
\hline Variable & Unit & Value \\
\hline Number of passengers (daily) & Person & 220,000 \\
\hline Number of stations & Station & 37 \\
\hline Average distance between stations & Meter & 500 \\
\hline Average travel time (peak hour) & Minute & 80 \\
\hline Route type & -- & Dedicated lane \\
\hline
\end{tabular}

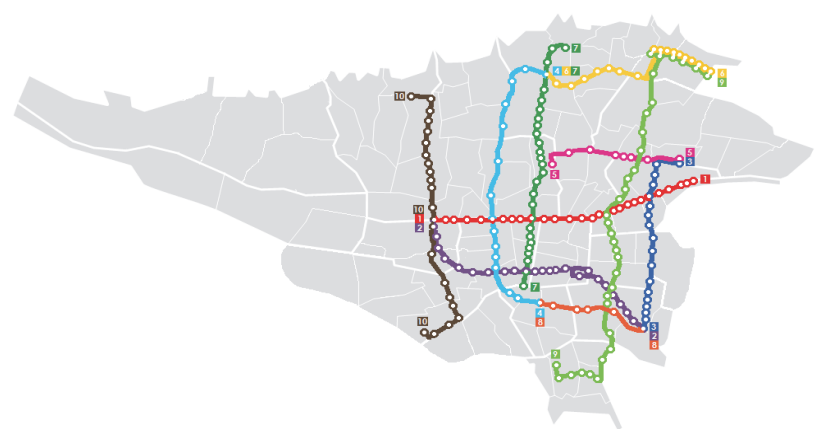

Figure 2 7th line of Tehran's BRT (The Dark Green line) [22]

Local authorities have taken some actions to control private car congestion and increase the share of public transportation in Tehran. Along the length of Valiasr Street $(18 \mathrm{~km})$, private cars are allowed to drive in one-way direction but BRTs move in two-way direction using dedicated bus lanes. Fig. 3 illustrates the Valiasr streetview according to field survey.
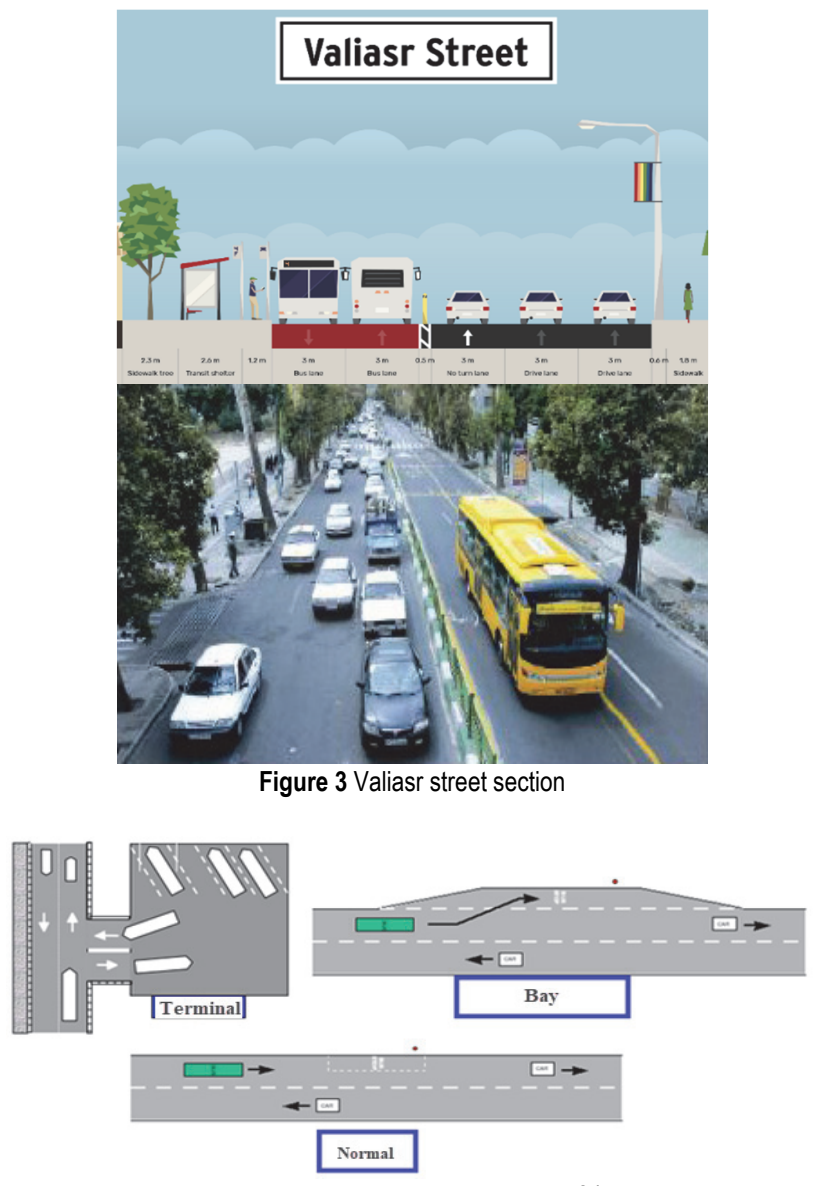

Figure 4 Aimsun bus station types [24] 


\section{TRAFFIC SIMULATION}

Aimsun as a microscopic traffic simulation tool has been used to simulate the operation of the 7 th line of Tehran's BRT. Two types of lanes, including general and reserved lanes can be modelled in Aimsun. On general lanes, all vehicles are allowed to drive but in reserved lanes only specific group of vehicles (e.g. public transportation) is allowed to drive. Reserved lanes may be of two types: compulsory or optional [24]. Regarding the field study, compulsory reserved lanes were modelled in Aimsun to be used by BRTs.

As illustrated in Fig. 4, there are three types of public transport stops in Aimsun, including normal, bus bay and terminal. In normal public transport stops, the public vehicles stop in the stop area. In bus bays, the vehicles stop outside the section nearby the public transport stop area and terminals are public transport stations with a certain capacity of vehicles. According to field survey, the first (Railway) and the last (Tajrish) stations are defined as terminals and intermediate stations are modelled as normal stations.

In order to simulate bus schedule, time headway of buses has been analysed and it was normally distributed with the mean of 5 minutes and standard deviation of 3 minutes. Another important parameter is stop-time at stations which was 25 seconds on average according to data derived from Tehran Bus Organization. With reference to the location of Line 7, many commercial and administrative centres are located along this line. Hence, many people use this line on a daily basis to get to work. So, the volume of traffic in the morning peak is used in the simulation.

In Aimsun, two types of TSP algorithms could be simulated, including Serve-All or Alternative. Serve-All serves all the remaining phases between the current green phase and the dwell phase with their minimum green time. The Alternative serves the dwell phase as soon as possible. The proposed TSP algorithm in Fig. 1 was used to prioritize BRT.

Because of different outputs of microscopic simulation tools, it is necessary to run the model several times. In this regard, 10 replications were considered according to results and previous studies, and finally an average of results was chosen as the output. The replication reduces variability in experimental results, and, therefore, increases the significance and confidence level of them.

Calibration means to adjust the model parameters to improve the model's ability to simulate local traffic characteristics and drivers' behaviour. It plays a crucial role in minimizing the differences between the simulation results and corresponding field measurements, such as traffic volumes, speed, and travel time. To obtain a close match between the observed and simulated traffic measurements, one has to perform a proper calibration of microscopic traffic simulation model parameters [25]. Among a large number of parameters in microscopic simulation, travel times and traffic volume data were chosen. According to Fig. 5, simulated and observed traffic volumes were compared and it was found that the simulation model has appropriate accuracy.

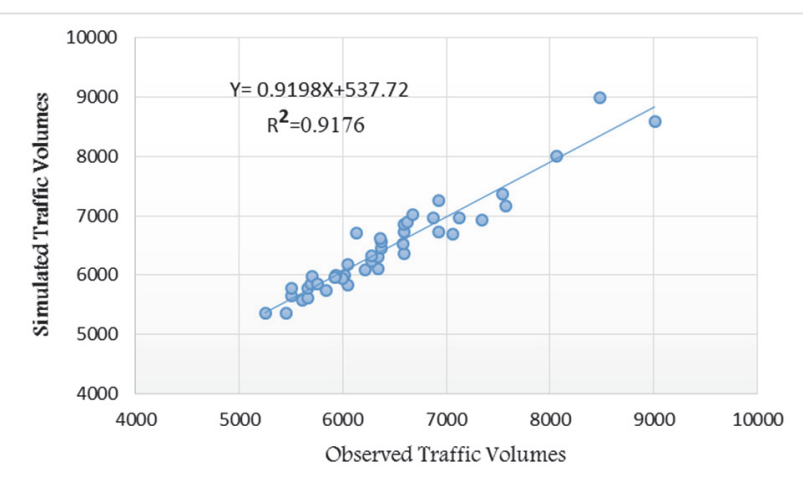

Figure 5 Comparison of field and simulated traffic volume

According to the outputs, simulated and observed travel times were compared and the difference was $1.23 \%$. Fig. 6 illustrates an intersection with dedicated bus lanes and TSP treatment operation in the simulation model.

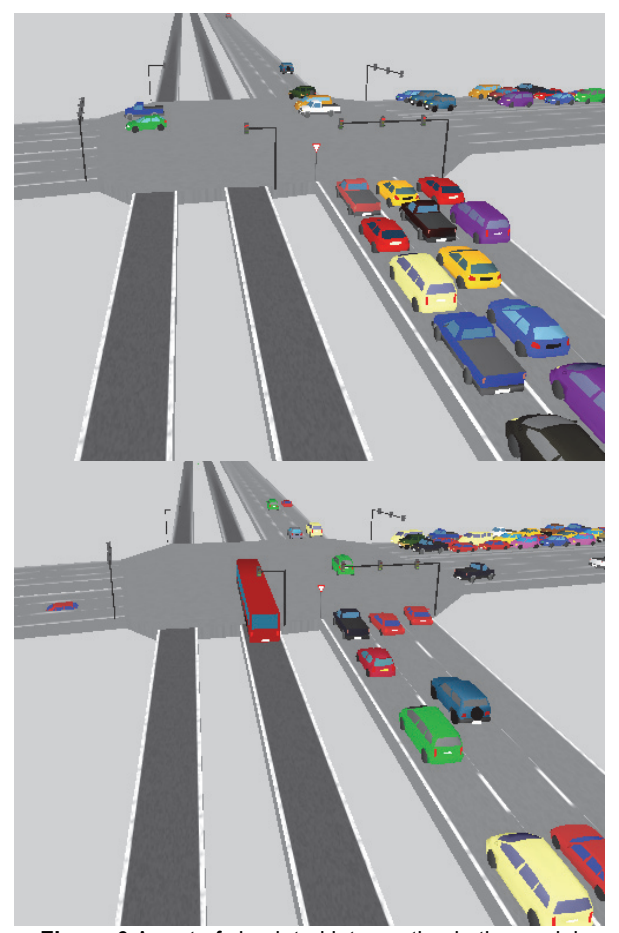

Figure $6 \mathrm{~A}$ part of simulated intersection in the model

\section{RESULTS AND DISCUSSION}

Various dimensions of the proposed scenario such as traffic, environmental and economic have been analyzed in this section.

\subsection{Primary Analysis of Traffic and Environmental Elements}

With respect to the importance of sustainability and reliability of public transportation systems, travel times, pollutant emissions and fuel consumption have been calculated and illustrated in Fig. 7. Regarding the fixed timing of intersections in scenario 1 (i.e. status quo), passengers experience long delays and stops at intersections due to the fixed traffic signal timing and allocation of green time was based on a predefined schedule instead of traffic volumes. In this regard, actuated traffic signals were simulated in scenario 2 and travel time 
reduced by $8 \%$ due to lower delays and stop times which is in accordance with Abbasi et al. (2020) findings. Since stop-and-go driving behaviour, long stop and reacceleration at intersections lead to higher pollutant emission rates and fuel consumption, in this regard, TSP and actuated traffic signals were simulated in the proposed scenario and $\mathrm{CO}, \mathrm{NOx}$ and fuel consumption reduced by $7.5 \%, 4.3 \%$ and $6.2 \%$, respectively. Fig. 8 illustrates the indicator changes of transit vehicles compared to the status quo. According to Fig. 8, buses experience lower delay using TSP and actuated traffic signals because the signal gives priority to buses when detected by detectors and regarding the proposed TSP algorithm, delays were reduced by $20.5 \%$ and average speed was increased by $8.4 \%$ which are in line with $[16,17]$ results.

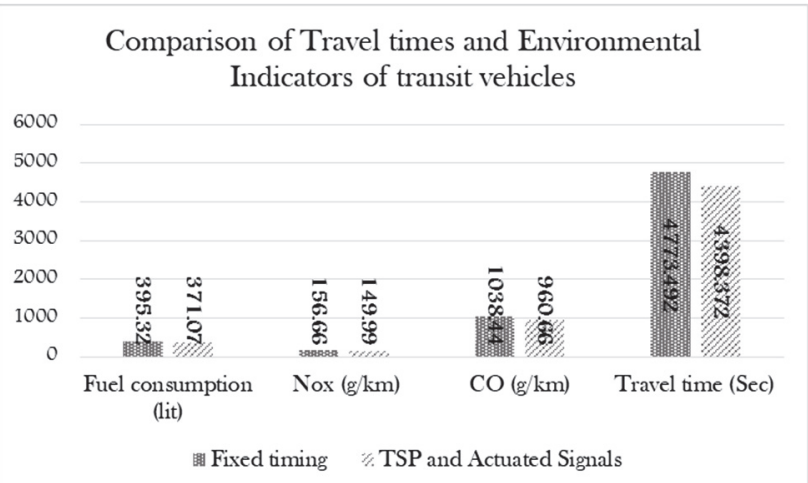

Figure 7 Comparison of Travel times and Environmental Indicators of transit vehicles

Traffic and Environmental indicator changes of transit vehicles (\%)

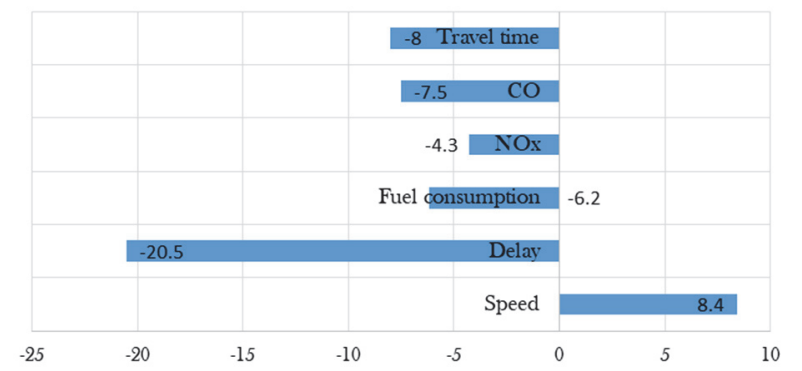

Figure 8 Traffic and Environmental indicator changes of transit vehicles using TSP

With respect to the importance of reducing congestion and delay for all users, different performance measures for non-transit vehicles were derived. TSP treatment reduces the delay and stop-times of transit vehicles and allocates the green phase to BRTs based on priority request. Nontransit vehicles might experience a lower level of service, increased delays and stop times. Fig. 9 illustrates the traffic indicators of non-transit vehicles. It can be calculated that by transit prioritizing, non-transit vehicles experience more travel times and delays at intersections. Travel times, stop times and delays increased by $2.59 \%, 11.25 \%$ and $8.81 \%$, respectively. Stop-and-go driving behaviour increases the fuel consumption [10]; according to Fig. 9, fuel consumption increases by $1.28 \%$ and speed reduces by $2.45 \%$. Because of stop and go driving behaviour and compacting vehicles at intersections, the density increases by $0.4 \%$ which shows that TSP does not significantly affect the queues of vehicles, which is in line with [18] results.

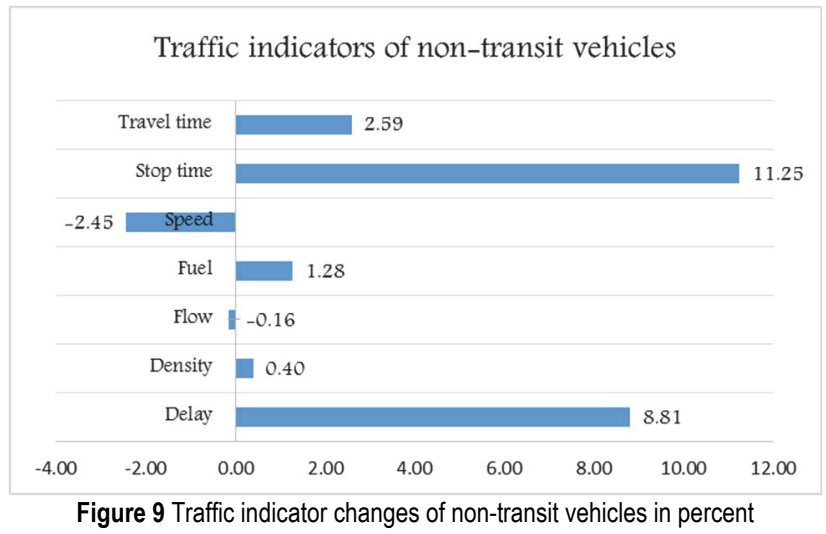

After implementation of TSP and actuated traffic signals, person based indicators have been derived and illustrated in Fig. 10. Regarding the actuated traffic signals, green time allocation is based on volume on approaches and TSP treatment gives priority to the public transportation system. Considering a large number of passengers in BRT and simulated scenarios, travel times, delays and stop times of people are reduced by $5.64 \%$, $2.07 \%$ and $2.6 \%$, respectively. It is clear that due to actuated traffic signal implementation, the mentioned indicators decrease. Lower stop times are leading to higher speed and flow in the network. In the proposed scenario, speed and flow increase by $1.59 \%$ and $1.2 \%$, respectively. Also, due to constant driving behaviour and elimination of re-acceleration and deceleration, fuel consumption decreased by $1.48 \%$. These findings and trends are in accordance with [16-17] results.

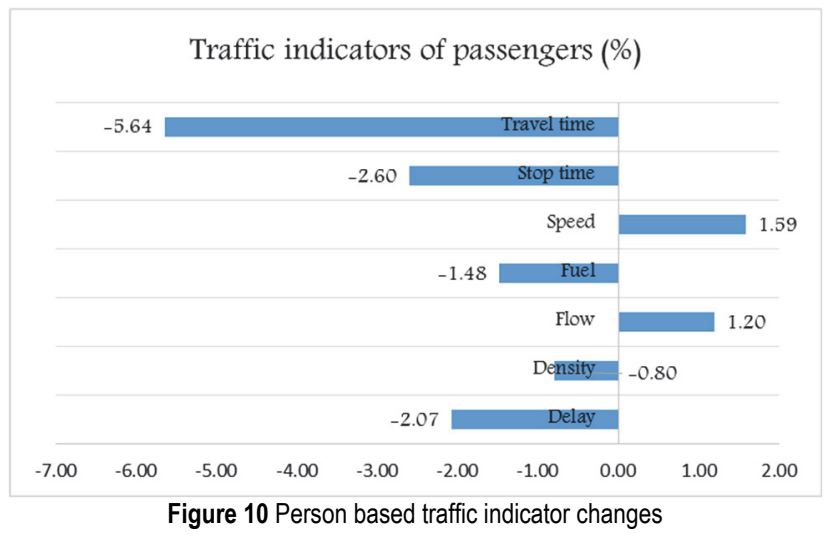

\subsection{Primary Analysis of Cost and Benefit Elements}

CBA is widely used to evaluate alternative courses of action that are designed to achieve appropriate policy objectives [26]. When travel time reduces, passengers experience lower travel time; all should be accounted for benefit analysis. The value of time (VOT) is defined as the opportunity cost of time and is a fraction of an individual's hourly wage. The value of time is also the first-order parameter used in cost-benefit analysis. Regarding the accessibility to passenger's data of transit vehicle, CBA has been conducted only for BRT passengers. According to data taken from the Statistical Centre of Iran in 2018 [22], the VOT is calculated according to Eq. (1): 


$$
V O T_{B}=\frac{S}{T \cdot 12 \cdot D}
$$

where $V O T_{B}$ is the $V O T$ of individuals $(\$ / \mathrm{hr}), S$ is the average household income per year $(\$), T$ is the average working hours per month (hr) and $D$ is the household size. Regarding passenger information and statistics published by the Central Bank of the Islamic Republic of Iran and the Bureau of Economic Statistics, the VOT is $1.5 \$$ (It should be noted that, 1 US Dollar $=42,105$ Iranian Rials (Exchange-rates, 2020)) per hour.

Considering VOT as $1.5 \$ / \mathrm{hr}$ while 220,000 passengers are commuting on a daily basis, then $12,55 \$$ million would be saved according to the travel time reduction.

In studies conducted by Boardman et al. (2017), CO and NOx cost reductions were estimated at 890 and 4,790 $\$ /$ Ton on average in 2016 , respectively [27]. The costs are related to some direct and indirect issues such as the cost of treatment due to related diseases like pulmonary and heart disease, as well as the cost of mental and psychological disorders. Regarding the CO, NOx emissions and fuel consumption reductions in the proposed scenario, it is expected to save $4.22 \$, 22.73 \$$ and $1.15 \$$ million annually, respectively.

Regarding the actuation of traffic signals, the implementation price should be accounted for CBA. Along the BRT route, among 20 intersections, 13 intersections are equipped with fixed traffic signals. According to the SRTS guideline, the purchase, installation and maintenance costs of actuated traffic signals are estimated to be $500,000 \$$ per intersection for a 4-leg approach intersection [28]. Therefore, $6.5 \$$ million is the cost for actuated traffic signal implementation.

The payback period (PP), Net Present Value (NPV) and Internal Rate of Return (IRR) have been used to assess the economic aspects of the proposed scenario. The payback period is the time taken to recover the initial investment i.e., the amount of time taken to break even on the investment. NPV is the difference between the present value of cash inflows and the present value of cash outflows over a period of time and IRR is a discount rate that makes the NPV of all cash flows equal to zero in a discounted cash flow analysis which is calculate based on Eq. (2) and Eq. (3), respectively.

$$
\begin{aligned}
& N P V=\sum \frac{C_{t}}{(1+r)^{t}} C_{O} \\
& \sum \frac{C_{t}}{(1+I R R)^{t}}=C_{O}
\end{aligned}
$$

where, $C_{O}$ is the initial investment, $C_{t}$ represents the cash flow and $r$ is the discount rate $(18 \%)$.

Costs include the purchase, installation and maintenance cost of actuated traffic signals and benefits include travel time saving, fuel consumption and pollutant emission reductions. The payback period is estimated to be 2 months after implementation, indicating a short-term policy which is in accordance with Abbasi et al. (2020) findings, Also the NPV and IRR are 10.9 \$ million and $113 \%$ annually, respectively.

\section{CONCLUSION}

In recent years, population and vehicle ownership growth have increased the congestion and delay in metropolises which made intersections as the main bottlenecks of urban traffic. Regarding the high volume of vehicles at intersections, traditional signal timing methods are inappropriate solutions because of fixed green time allocation to different approaches of intersections. The $7^{\text {th }}$ line of Tehran's BRT is one of the longest $(18 \mathrm{~km})$ public transportation lines in Tehran and passengers experience long delays because of fixed traffic signals. Due to space limitation, an increase in supply is not possible and using signal timing methods such as actuated signals and public transportation priority are potential solutions. Despite numerous intersections along the route of the $7^{\text {th }}$ line of Tehran's BRT, no intersection is equipped with Transit Signal Priority (TSP) treatment and among 20 intersections, 13 intersections are signalized but none of them are actuated.

According to previous studies, simulation is capable of studying systems that are in the design phase. Microscopic traffic simulation tool, Aimsun has been used to study TSP and actuated signals in Tehran's BRT. The original contributions of this paper are to study the operation of BRT line instead of an isolated intersection or an arterial road. Another contribution of this paper is considering the economic aspects of scenario and conducting a cost-benefit analysis. Also, less attention has been paid to the pollutant emissions and fuel consumption of transit and non-transit vehicles. Regarding the importance of longitudinal slope in fuel consumption and pollutant emissions, this factor has been considered in this paper. In addition, unlike previous studies, this paper focuses on the overall bus schedule rather than a single trip.

Regarding the importance of different aspects of proposed scenario, traffic, economic and environmental impacts have been analysed for transit and non-transit vehicles. Results show that by implementation of TSP and actuated traffic signals, traffic indicators such as travel times, delays and stop times of people will be reduced by $5.64 \%, 2.07 \%$ and $2.6 \%$, respectively. Speed and flow of vehicles will increase by $1.59 \%$ and $1.2 \%$ due to the lower stop times, respectively. Besides, fuel consumption will be decreased due to the constant driving behaviour and elimination of re-acceleration and deceleration by $1.48 \%$. In terms of cost-benefit analysis (CBA), costs include the purchase, installation and maintenance cost of actuated traffic signals and benefits include travel time saving, fuel consumption and pollutant emission reductions. The Net Present Value (NPV), Internal Rate of Return (IRR) and payback period were calculated and found the proposed scenario as a profitable and short-term policy.

It is difficult and sometimes impossible to evaluate all the costs involved in transportation systems. In this sense, it is recommended for further research to consider the impact of noise pollution and people shifting to BRT regarding the increase in utility of public transportation.

It is important to note that the presented use case is operatively limited regarding the availability of real-time data exchange with other public transport subsystems. Cooperation and data exchange between main subsystems of the traffic system is today crucial because drivers, 
vehicles and infrastructure are no longer independent, they cooperate in order to improve the quality of public transport system in general [29]. And, by implementation of a true cooperative concept, it can be improved. Also, there is a possibility for implementation of urban mobility estimation subsystem that real-time estimates state of public transport (transport demand and supply) [30]. This information can be included in real-time priority subsystem optimization.

\section{Acknowledgements}

The research presented in this paper is partially realized within the EU's Erasmus+ program supported by the University of Zagreb Program Funds Support for scientific and artistic research (2020) through the project: "Innovative models and control strategies for intelligent mobility".

\section{REFERENCES}

[1] Financial Tribune, (2017, February 15). Retrieved from https://financialtribune.com/articles/economy-domesticeconomy/59702/tehran-traffic-losses-hit-21b-pa.

[2] IEA. (2015). CO2 Emissions from Fuel Combustion 2015, CO2 Emissions from Fuel Combustion. OECD Publishing, Paris. https://doi.org/10.1787/co2_fuel-2015-en

[3] Hao, Y., Wang, Y., \& Yang, X. (2014, October). A schedulebased coordinated optimization model for Transit Signal Priority under Connected Vehicle environment. In 17th International IEEE Conference on Intelligent Transportation Systems (ITSC), 2578-2583. https://doi.org/10.1109/ITSC.2014.6958103

[4] Pedroso, G., Bermann, C., \& Sanches-Pereira, A. (2018). Combining the functional unit concept and the analytic hierarchy process method for performance assessment of public transport options. Case Studies on Transport Policy, 6(4), 722-736. https://doi.org/10.1016/j.cstp.2018.09.002

[5] Zhou, L., Wang, Y., \& Liu, Y. (2017). Active signal priority control method for bus rapid transit based on vehicle infrastructure integration. International Journal of Transportation Science and Technology, 6(2), 99-109. https://doi.org/10.1016/j.ijtst.2017.06.001

[6] Gholami, A. \& Tian, Z. (2016). Designing the required changes in the bus network after performing limited traffic zone in Mashhad, Iran. Case Studies on Transport Policy, 4(2), 161-167. https://doi.org/10.1016/j.cstp.2016.03.003

[7] Vujić, M., Mandzuka, S., \& Greguric, M. (2015). Pilot implementation of public transport priority in the city of Zagreb. Promet-Traffic \& Transportation, 27(3), 257-265. https://doi.org/10.7307/ptt.v27i3.1735

[8] Deng, T., Ma, M., \& Wang, J. (2013). Evaluation of bus rapid transit implementation in China: Current performance and progress. Journal of Urban Planning and Development, 139(3), 226-234. https://doi.org/10.1061/(ASCE)UP.1943-5444.0000150

[9] Sharma, H. K., Swami, M., \& Swami, B. L. (2012). Optimizing performance of at-grade intersection with bus rapid transit corridor and heterogeneous traffic. International Journal of Transportation Science and Technology, 1(2), 131-145. https://doi.org/10.1260/2046-0430.1.2.131

[10] Abbasi, M., Hosseinlou, M. H., \& JafarzadehFadaki, S. (2020). An investigation of Bus Rapid Transit System (BRT) based on economic and air pollution analysis (Tehran, Iran). Case Studies on Transport Policy, 8(2), 553-563. https://doi.org/10.1016/j.cstp.2019.11.008
[11] Smith, H. R., Hemily, B., \& Ivanovic, M. (2005). Transit signal priority (TSP): A planning and implementation handbook.

[12] Al-Deek, H., Sandt, A., Alomari, A., \& Hussain, O. (2017). A technical note on evaluating the effectiveness of bus rapid transit with transit signal priority. Journal of Intelligent Transportation Systems, 21(3), 227-238. https://doi.org/10.1080/15472450.2017.1286987

[13] Oliveira-Neto, F. M., Loureiro, C. F. G., \& Han, L. D. (2009). Active and passive bus priority strategies in mixed traffic arterials controlled by SCOOT adaptive signal system: Assessment of performance in Fortaleza, Brazil. Transportation research record, 2128(1), 58-65. https://doi.org/10.3141/2128-06

[14] Davol, A. P. (2001). Modeling of traffic signal control and transit signal priority strategies in a microscopic simulation laboratory. Doctoral dissertation, Massachusetts institute of technology.

[15] Baker, R. J., Collura, J., Dale, J. J., Head, L., Hemily, B., Ivanovic, M., Jarzab, J. T., McCormick, D., Obenberger, J., Smith, L., \& Stoppenhagen, G. R. (2002). An overview of transit signal priority (No. Final Draft).

[16] Vilarinho, C., Tavares, J. P., \& Rossetti, R. J. (2017). Intelligent traffic lights: Green time period negotiaton. Transportation research procedia, 22, 325-334. https://doi.org/10.1016/j.trpro.2017.03.039

[17] Ilahi, A. \& Irawan, M. Z. (2013). A microsimulation model of median busway and ATCS (case study: Transjogja Bus, Yogyakarta, Indonesia). In Proceedings of the Eastern Asia Society for Transportation Studies, 9, 350. Eastern Asia Society for Transportation Studies.

[18] Shaaban, K. \& Ghanim, M. (2018). Evaluation of transit signal priority implementation for bus transit along a major arterial using microsimulation. Procedia computer science, 130, 82-89. https://doi.org/10.1016/j.procs.2018.04.015

[19] Ghanim, M. S., Abu-Lebdeh, G., \& Ahmed, K. (2013, April). Microscopic simulation study of transit signal priority implementation along an arterial corridor. In 2013 5th International Conference on Modeling, Simulation and Applied Optimization (ICMSAO), 1-4. https://doi.org/10.1109/ICMSAO.2013.6552718

[20] Yang, M., Wang, B., Wang, W., Chen, X., \& Zhou, W. (2012). A microscopic simulation of transit speed guidance and signal priority using advanced detection to make BRT more efficient (No. 12-2206).

[21] Wang, M. \& Weng, J. (2010). Research on the BRT Priority Signal Optimization Methods Based on Actuated Control. In 17th ITS World Congress ITS Japan ITS America ERTICO.

[22] Transportation and Traffic organization of Tehran Municipality (TTOTM). (2020). Review of Comprehensive Statistics and Information of Tehran. Retrieved from http://www.tehran.ir/, (accessed 5 January 2020).

[23] Seyedabrishami, S., Mamdoohi, A., Barzegar, A., \& Hasanpour, S. (2012). Impact of carpooling on fuel saving in urban transportation: case study of Tehran. Procedia-Social and Behavioral Sciences, 54, 323-331. https://doi.org/10.1016/j.sbspro.2012.09.751

[24] TSS-Transport Simulation Systems. (2008). AIMSUN User's Manual version 6.

[25] Yu, M. \& Fan, W. D. (2017). Calibration of microscopic traffic simulation models using metaheuristic algorithms. International Journal of Transportation Science and Technology, 6(1), 63-77. https://doi.org/10.1016/j.jitst.2017.05.001

[26] Baik, S., Davis, A. L., \& Morgan, M. G. (2019). Illustration of a Method to Incorporate Preference Uncertainty in Benefit-Cost Analysis. Risk Analysis, 39(11), 2359-2368. https://doi.org/10.1111/risa.13338

[27] Boardman, A. E., Greenberg, D. H., Vining, A. R., \& Weimer, D. L. (2017). Cost-benefit analysis: concepts and 


$$
\text { practice. Cambridge University Press. }
$$
https://doi.org/10.1017/9781108235594

[28] SRTS. (2020, March 18). Retrieved from Safe route to school:http://guide.saferoutesinfo.org/engineering/traffic_si gnals.cfm.

[29] Mandžuka, S., Škorput, P., \& Vujić, M. (2015). Architecture of cooperative systems in traffic and transportation. In 2015 23rd Telecommunications Forum Telfor (TELFOR). 25-28. https://doi.org/10.1109/TELFOR.2015.7377386

[30] Vidović, K., Mandžuka, S., \& Brčić, D. (2017). Estimation of urban mobility using public mobile network. In 2017 International Symposium ELMAR, 21-24. https://doi.org/10.23919/ELMAR.2017.8124426

\section{Contact information:}

Mohammadhossein ABBASI, PhD Student

(Corresponding author)

Tarbiat Modares University, Tehran, Iran

Jalal AleAhmad, Nasr, 14115-111

E-mail: A_mohammadhossein@modares.ac.ir

Mansour Hadji HOSSEINLOU, Associated Professor

K. N. Toosi University of Technology,

Mirdamad Blvd, No. 470, Tehran, Iran

E-mail: mansour@kntu.ac.ir

Arash SARRESHTEHDARI, Master of Science Student

Sapienza University of Rome,

Via Eudossiana, 18, 00184, Rome, Italy

E-mail: sarreshtehdari.1861718@studenti.uniroma1.it

Sadko MANDZUKA, Professor

ITS Department, University of Zagreb,

Vukeliceva 4, 10000, Zagreb, Croatia

E-mail: sadko.mandzuka@fpz.hr 